\title{
Neoadjuvant treatment in pancreatic cancer: Evidence-based medicine? A systematic review and meta-analysis
}

\author{
Francesco D'Angelo $^{1}$ - Laura Antolino ${ }^{1}$ - Alessio Farcomeni ${ }^{2} \cdot$ Dario Sirimarco $^{1}$ • \\ Andrea Kazemi Nava ${ }^{1} \cdot$ Martina De Siena $^{1} \cdot$ Niccolò Petrucciani $^{1,3}$. \\ Giuseppe Nigri $^{1}$ - Stefano Valabrega ${ }^{1}$ - Paolo Aurello ${ }^{1}$ - Giovanni Ramacciato ${ }^{1}$
}

Received: 25 March 2017 / Accepted: 4 April 2017/Published online: 8 April 2017

(C) Springer Science+Business Media New York 2017

\begin{abstract}
Neoadjuvant treatment in non-metastatic pancreatic cancer $(\mathrm{PaC})$ has the theoretical advantages of downstaging the tumor, sterilizing any present systemic undetectable disease, selecting patients for surgery and administering therapy to each patient. The aim of this systematic review is to analyze the state of the art on neoadjuvant protocols for non-metastatic PaC. A literature search over the last 10 years was conducted, and papers had to be focused on resectable, borderline resectable (BLR) or locally advanced (LA) histo- or cytologically proven $\mathrm{PaC}$; to be prospective studies or prospectively collected databases; to report percentage of protocol achievement and survival data at least in an intention-to-treat (ITT) analysis. Twelve studies were eligible for systematic review. Studies included a total of 624 patients: 248 resectable, 268 BLR, 71 LA and 37 nonspecified. All studies were included for meta-analysis. ITT overall survival (OS) was 16.7 months $(95 \%$ CI 15.16-18.26 months); for resected patients OS was 22.78 months (95\% CI 20.42-25.16), and for eventually non-resected patients it was 9.89 months (95\% CI 8.84-10.96). Neoadjuvant approaches for resectable, BLR and LA PaC are spreading. Outcomes tend to be better outside an RCT
\end{abstract}

Laura Antolino

laura.antolino@uniroma1.it

1 Division of General Surgery, Department of Medical and Surgical Sciences and Translational Medicine, UOC Chirurgia 3, Sapienza University, St. Andrea Hospital, Via di Grottarossa 1035-1039, 00189 Rome, Italy

2 Department of Public Health and Infectious Diseases, Sapienza University, Rome, Italy

3 Digestive Surgery and Liver Transplantation Unit, Nice University Hospital, Nice, France context, but strong evidences are lacking. Actually such treatments should be performed only in a randomized clinical trial setting.

Keywords Pancreatic cancer - Neoadjuvant therapy · Survival $\cdot$ Borderline $\cdot$ Resectable $\cdot$ Surgery

\section{Introduction}

Pancreatic cancer $(\mathrm{PaC})$ is one of the most challenging global health burdens that physicians are facing nowadays. Its 5-year survival in non-metastatic stages ranges between 3 and $14 \%$ [1], while surgery remains the only chance for long survivors. Currently, the standard of care advocates a surgery-first approach in resectable situations followed by adjuvant treatment, but neoadjuvant approaches are spreading either in resectable and in borderline resectable (BLR) and locally advanced (LA) patients. Whether this attitude provides to the patient a survival advantage is a widespread belief but not a matter of fact. The National Comprehensive National Network states that there is limited evidence to recommend specific neoadjuvants regimens off-study [2]. While the only choice in LA $\mathrm{PaC}$ is a loco-regional chemoradiation or systemic chemotherapy and subsequent revaluation, for resectable and BLR we must choose between a surgery-first approach and a neoadjuvant treatment. Over $40 \%$ of patients who have clinically a resectable disease are found unresectable at surgery, even though this percentage drops to $20 \%$ if a diagnostic laparoscopy is added to the preoperative diagnostic panel [3], and one out of five patients are eventually misdiagnosed as resectable or BLR while having a LA disease. Moreover, $27 \%$ of BLR patients will require a vascular resection in order to achieve their pancreatectomy 
[4], but histologic invasion of resected vessel will be confirmed only in $56.7 \%$ of specimens [5]. Finally, up to $28 \%$ of successfully resected patients will not undergo adjuvant therapies because of surgical morbidity, poor performance status, refusal or early recurrence [5]. A preoperative treatment has the theoretical advantages of delivering systemic therapy to all patients in a healthy tumor bed and identifying tumors with an aggressive biology and thus patients who would not benefit from surgery.

The aim of this systematic review is to analyze the bulk of knowledge on neoadjuvant protocols for non-metastatic pancreatic cancer and derive a meta-analysis of its results.

\section{Materials and methods}

Following the criteria of the PRISMA statement, a comprehensive PubMed, Embase and Cochrane library search was conducted looking for studies focusing on neoadjuvant therapies in non-metastatic pancreatic cancer. The keywords used were 'pancreatic cancer or carcinoma' and 'neoadjuvant therapy or treatment.' The research was restricted to the last 10 years (June 2006-June 2016) and to English language articles dealing with human patients. Papers had to be focused on resectable, borderline resectable or locally advanced histo- or cytologically proven pancreatic adenocarcinoma; to be prospective studies or prospectively collected databases; to report the percentage of protocol achievement and survival data at least in an intention-to-treat (ITT) analysis. Exclusion criteria were retrospective studies, RCT papers, periampullary cancers and missing outcomes data. Data extraction was carried out by two independent investigators. Primary outcome was ITT overall survival (OS), and secondary outcomes were protocol achievement, R0 resection rate, specific resectable, resected and unresected OS.

Pooled survival times and proportions were computed by means of meta-analyses. Each separate meta-analysis conducted was strictly under heterogeneity among studies, by means of a hierarchical Bayesian model. Homogeneity was not assessed due to the limited number of studies, and instead we worked under heterogeneity through hierarchical models [6]. Median survival times and logistic transforms of proportions were assumed to be normally distributed. Each study summary was assumed to arise from a Gaussian centered on a study-specific effect and with variance corresponding to the square of its estimated standard error, inflated by $25 \%$ in order to guarantee conservative statements. The study-specific summary was assumed to be Gaussian, centered on an unknown pooled measure, which was the main object of interest. Summaries for proportions were then back-transformed appropriately. As per guidelines with limited number of studies involved, informative priors were used. For the variance of the pooled measures, we assumed an inverse Gamma centered on an estimator obtained with a moment-based approach (inflated by $25 \%$ for similar reasons as above). Potential publication bias was estimated using Egger's linear regression tests, which were never significant.

The systematic review's protocol was regularly registered at www.researchregistry.com with the unique identifying number of review registry 102 .

\section{Results}

\section{Papers selection and systematic review}

The extensive literature search led to the identification of 612 English papers over the past 10 years focusing on neoadjuvant treatment for resectable, BLR and LA PaC, of which 12 papers eligible for the systematic review (Fig. 1) [7-18]. Papers were published over a 8-year period, between 2008 and 2015 .

\section{Studies characteristics}

Studies included between 15 and 246 patients, with a total of 624 patients: 248 resectable, 268 borderline resectable, 71 locally advanced and 37 non-specified (Table 1). Four papers were restricted to resectable patients [9, 12, 17, 18], one to LA patients [8] and one to BLR patients [10]. Treatment plans included: six studies offer a systemic chemotherapy $[9,11,13,15,16,18]$, three a loco-regional chemoradiation regimen $[8,12,17]$ and three a combination of the two [7, 10, 14]. Gemcitabine has been the most widely used antineoplastic agent (Table 1). All studies reported ITT-OS. One study didn't report OS neither for eventually resected patients nor for post-neoadjuvant unresectable patients [12]. Two studies didn't report OS for post-neoadjuvant unresectable patients [9, 18]. One study didn't report resection margins [8].

\section{Definition of resectability}

The definition of resectability varies among studies (Table 2). The most cited classification [10, 14-16] is Callery's one from the expert consensus statement sponsored by the American Hepato-Pancreato-Biliary Association and others [19]. Five studies used their own definitions $[9,11,12,17,18]$.

\section{Protocol achievement}

The ITT population includes 624 patients submitted to neoadjuvant therapy. A total of 395 patients eventually 


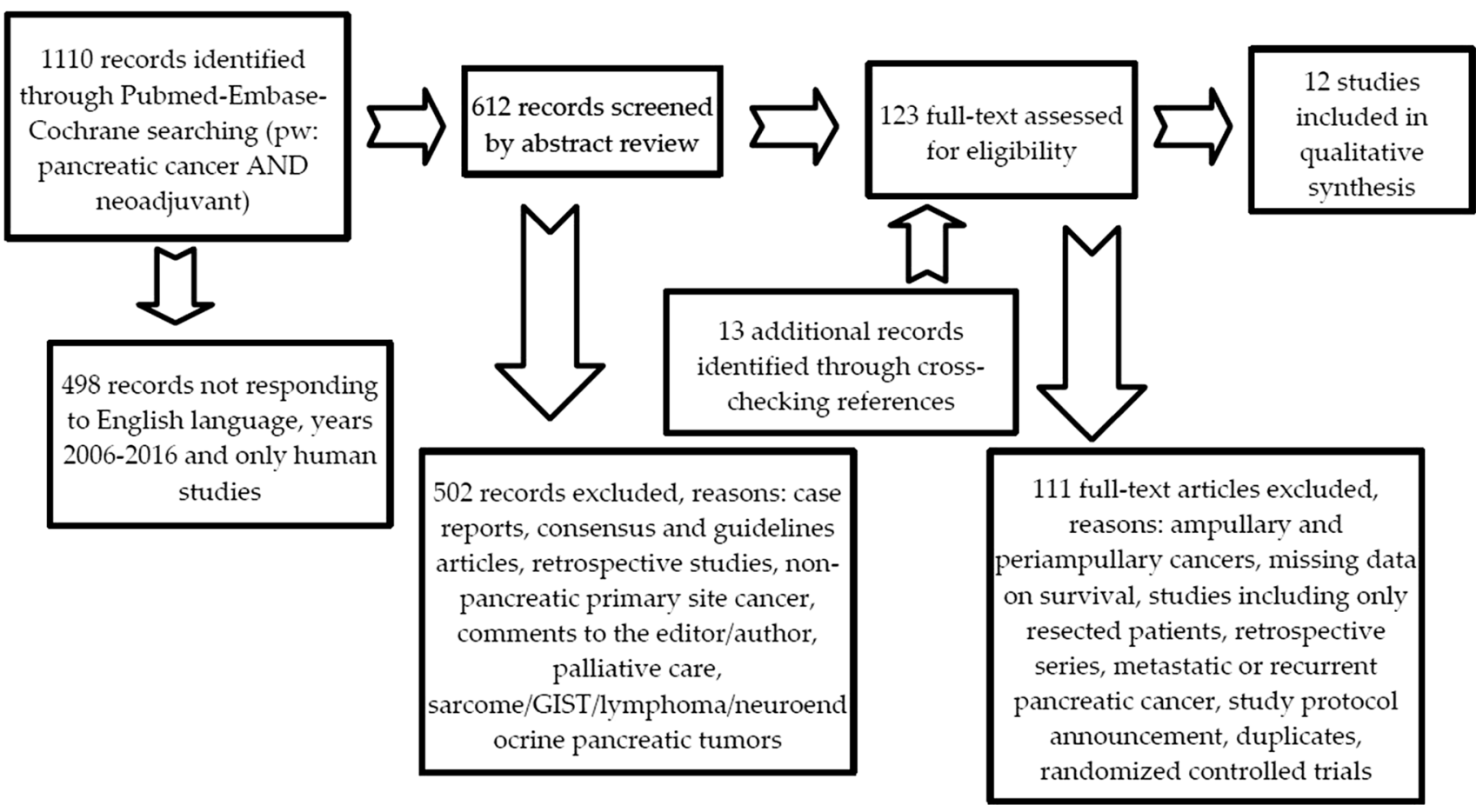

Fig. 1 Studies' selection flow chart

underwent surgical resection with curative intent. Protocol achievement in terms of completion of the proposed neoadjuvant treatment followed by pancreatectomy ranged 26.7-89.28\% (Table 1), and at the meta-analysis it was $65 \%(95 \%$ CI $62-67 \%)$ with a regression test of $p=0.366$ (Fig. 2).

\section{Resection margins}

One paper failed to report data on resection margins [8]. Of the 395 resected patients, 391 resection margins were specified: $355 \mathrm{R} 0,35 \mathrm{R} 1$ and $1 \mathrm{R} 2$. R0 rate ranged $69.2-100 \%$ (Table 1), and at the meta-analysis it was $94 \%$ (95\% CI 93-95\%) with a regression test of $p=0.0913$ (Fig. 3).

\section{Survival}

Intention-to-treat overall survival ranged 13.5-27.2 months (Table 1), and at the meta-analysis ITT-OS was 16.7 months (95\% CI 15.16-18.26 months) with a regression test of $p=0.1087$ (Fig. 4).

OS of eventually resected patients ranged 15-36.5 months (Table 1), and at the meta-analysis resected OS was 22.78 months (95\% CI 20.42-25.16 months) with a regression test of $p=0.0582$ (Fig. 5).

Finally OS of post-neoadjuvant treatment unresectable patients ranged 8.6-13.2 months (Table 1), and at the meta-analysis unresectable OS was 9.89 months $(95 \%$
CI 8.84-10.96 months) with a regression test of $p=0.379$ (Fig. 6).

We conducted a subgroup analysis of studies dealing with resectable only patients [9, 12, 17, 18], and this analysis takes into account a total of 123 patients: ITT-OS in this setting ranged 15.5-27.2 months (Table 1), and at the meta-analysis resectable ITT-OS was 18.16 months (95\% CI 14.08-22.45 months) with a regression test of $p=0.5293$ (Fig. 7).

Among those studies restricted to resectable patients, three reported OS of eventually resected patients [9, 17, 18]: 69 out of 97 clinically resectable patients have been resected. The OS of eventually resected patients in this setting ranged 19.1-32 months, and at the meta-analysis it was 20.87 months (95\% CI 17.97-23.82 months) with a regression test of $p=0.5205$ (Fig. 8).

\section{Discussion}

RCTs focusing on neoadjuvant therapies are lacking, and the existing three trials conducted on resectable $\mathrm{PaC}$ report a protocol achievement of $18.18-70 \%$ and an ITT survival of 9.9-19.4 months [23]: Palmer et al. [24] report a resection rate of 54\% after neoadjuvant treatment, of which $75 \%$ R0 resections; Golcher reports a non-statistically significant difference of resection rate in the neoadjuvant group $(57.57 \%)$ versus the upfront surgery group (69.69\%), and there is to say that this study has been terminated 


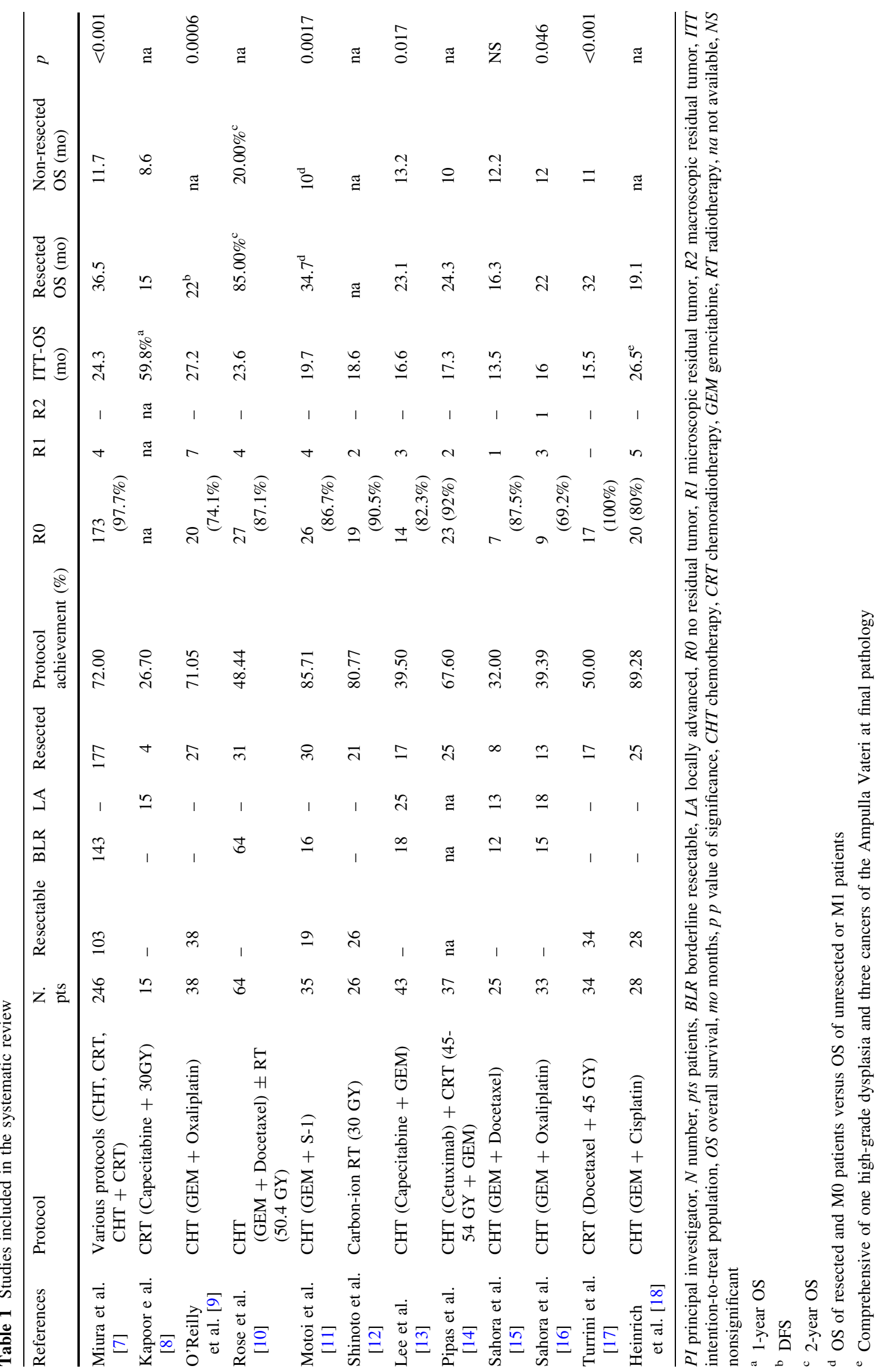


Table 2 Definitions of resectable, borderline resectable and locally advanced pancreatic cancer among studies

\begin{tabular}{|c|c|c|c|c|}
\hline References & Resectable & Borderline resectable & Locally advanced & $\begin{array}{l}\text { Reference } \\
\text { classification }\end{array}$ \\
\hline $\begin{array}{l}\text { Miura } \\
\text { et al. [7] }\end{array}$ & $\begin{array}{l}\text { No CA/SMA/HA abutment; SMV, } \\
\text { PV or SMV-PV confluence } \\
\text { narrowing }<50 \%\end{array}$ & $\begin{array}{l}\text { SMA or CA abutment }<180^{\circ} \text {; } \\
\text { abutment or short encasement of } \\
\text { HA; SMV, PV or SMV-PV } \\
\text { confluence narrowing }>50 \% \text { or } \\
\text { short segment occlusion (allowing } \\
\text { for reconstruction); suspicion (not } \\
\text { diagnosis) of metastatic disease }\end{array}$ & $\begin{array}{l}\text { SMA/CA encasement } \\
>180^{\circ} \text {; occlusion of SMV, } \\
\text { PV or SMV-PV } \\
\text { confluence not allowing } \\
\text { for reconstruction }\end{array}$ & Appel et al. [20] \\
\hline $\begin{array}{l}\text { Kapoor } \\
\text { et al. [8] }\end{array}$ & - & - & $\begin{array}{l}\text { Encasement/involvement of } \\
\text { SMA/CA }\end{array}$ & Tempero et al. [21] \\
\hline $\begin{array}{l}\text { O'Reilly } \\
\text { et al. [9] }\end{array}$ & $\begin{array}{l}\text { Clear fat plane around CA and SMA, } \\
\text { patent SMV/PV, no SMV } \\
\text { encasement or PV involvement, no } \\
\text { HA or SMA encasement, no extra- } \\
\text { regional nodal disease }\end{array}$ & - & - & - \\
\hline $\begin{array}{l}\text { Rose et al. } \\
\text { [10] }\end{array}$ & $\begin{array}{l}\text { No evidence of SMV or PV } \\
\text { abutment, distortion, tumor } \\
\text { thrombus or venous encasement } \\
\text { and clear fat planes around CA, HA } \\
\text { and SMA }{ }^{\text {a }}\end{array}$ & $\begin{array}{l}\text { Involvement of SMV/PV allowing } \\
\text { for reconstruction, GDA or HA } \\
\text { involvement/encasement w/o } \\
\text { extension to CA or abutment of } \\
\text { SMA }<180^{\circ a}\end{array}$ & $\begin{array}{l}\text { Major venous thrombosis of } \\
\text { PV/SMV, encasement of } \\
\text { SMA, CA or proximal } \\
\text { HA }^{\mathrm{a}}\end{array}$ & Callery et al. $[19]^{\mathrm{a}}$ \\
\hline $\begin{array}{l}\text { Motoi } \\
\text { et al. } \\
{[11]}\end{array}$ & - & $\begin{array}{l}\text { Encasement of PV/SMV and/or } \\
\text { abutment of HA or SMA within } \\
180^{\circ}\end{array}$ & - & - \\
\hline $\begin{array}{l}\text { Shinoto } \\
\text { et al. } \\
\text { [12] }\end{array}$ & No involvement of HA, CA or SMA & - & - & - \\
\hline $\begin{array}{l}\text { Lee et al. } \\
\text { [13] }\end{array}$ & $\begin{array}{l}\text { Clear tissue plane around SMA, CA, } \\
\mathrm{HA} \text { and SMV/PV }\end{array}$ & $\begin{array}{l}\text { SMA or CA abutment or GDA } \\
\text { encasement up to origin of HA or } \\
\text { SMV short segment occlusion }\end{array}$ & $\begin{array}{l}\text { SMA or CA or HA } \\
\text { encasement or SMV/PV } \\
\text { occlusion }\end{array}$ & $\begin{array}{l}\text { NCCN Pancreatic } \\
\text { Adenocarcinoma } \\
\text { Guidelines } \\
\text { version } 1.2008 \\
\text { [22] }\end{array}$ \\
\hline $\begin{array}{l}\text { Pipas et al. } \\
\text { [14] }\end{array}$ & $\begin{array}{l}\text { No evidence of SMV or PV } \\
\text { abutment, distortion, tumor } \\
\text { thrombus or venous encasement } \\
\text { and clear fat planes around CA, HA } \\
\text { and SMA }\end{array}$ & $\begin{array}{l}\text { Involvement of SMV/PV allowing } \\
\text { for reconstruction, GDA or HA } \\
\text { involvement/encasement w/o } \\
\text { extension to CA or abutment of } \\
\text { SMA }<180^{\circ}\end{array}$ & $\begin{array}{l}\text { Major venous thrombosis of } \\
\text { PV/SMV, encasement of } \\
\text { SMA, CA or proximal HA }\end{array}$ & Callery et al. [19] \\
\hline $\begin{array}{l}\text { Sahora } \\
\text { et al. } \\
{[15]}\end{array}$ & $\begin{array}{l}\text { No evidence of SMV or PV } \\
\text { abutment, distortion, tumor } \\
\text { thrombus or venous encasement } \\
\text { and clear fat planes around CA, HA } \\
\text { and SMA }\end{array}$ & $\begin{array}{l}\text { Involvement of SMV/PV allowing } \\
\text { for reconstruction, GDA or HA } \\
\text { involvement/encasement w/o } \\
\text { extension to CA or abutment of } \\
\text { SMA }<180^{\circ}\end{array}$ & $\begin{array}{l}\text { Major venous thrombosis of } \\
\text { PV/SMV, encasement of } \\
\text { SMA, CA or proximal HA }\end{array}$ & Callery et al. [19] \\
\hline $\begin{array}{l}\text { Sahora } \\
\text { et al. } \\
{[16]}\end{array}$ & $\begin{array}{l}\text { No evidence of SMV or PV } \\
\text { abutment, distortion, tumor } \\
\text { thrombus or venous encasement } \\
\text { and clear fat planes around CA, HA } \\
\text { and SMA }\end{array}$ & $\begin{array}{l}\text { Involvement of SMV/PV allowing } \\
\text { for reconstruction, GDA or HA } \\
\text { involvement/encasement w/o } \\
\text { extension to CA or abutment of } \\
\text { SMA }<180^{\circ}\end{array}$ & $\begin{array}{l}\text { Major venous thrombosis of } \\
\text { PV/SMV, encasement of } \\
\text { SMA, CA or proximal HA }\end{array}$ & Callery et al. [19] \\
\hline $\begin{array}{l}\text { Turrini } \\
\text { et al. } \\
{[17]}\end{array}$ & $\begin{array}{l}\text { Involvement of SMV/PV }<180^{\circ} \text {, no } \\
\text { occlusion of SMV or PV } \\
\text { confluence, no extension to SMA or } \\
\text { CA, no extrahepatic disease }\end{array}$ & - & - & - \\
\hline $\begin{array}{l}\text { Heinrich } \\
\text { et al. } \\
\text { [18] }\end{array}$ & $\begin{array}{l}\text { cT1, cT2, cT3s. AJCC classification } \\
\text { 7th ed. }\end{array}$ & - & - & - \\
\hline
\end{tabular}

$P I$ principal investigator, $S M V$ superior mesenteric vein, $P V$ portal vein, $H A$ hepatic artery, $C A$ celiac axis, $S M A$ superior mesenteric artery, $G D A$ gastroduodenal artery, w/o without, AJCC American Joint Committee on Cancer

${ }^{\text {a }}$ Criteria specified at restaging 


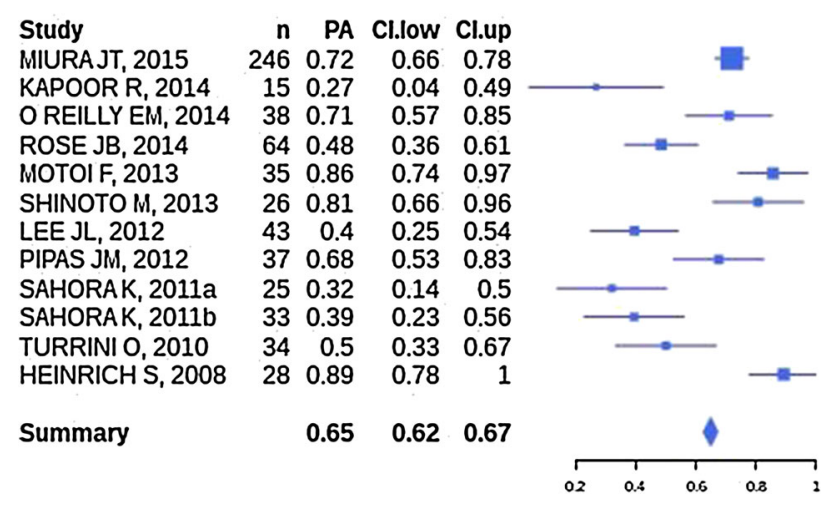

Fig. 2 Forest plot protocol achievement

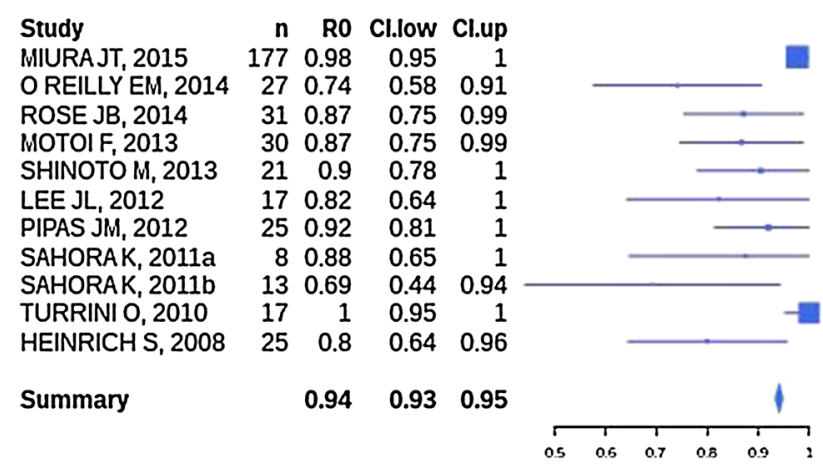

Fig. 3 Forest plot R0

because of the poor recruitment rate and did not reach the necessary sample size [25]; Landry reported a resection rate of $23.8 \%$ after neoadjuvant treatment of locally advanced potentially resectable $\mathrm{PaC}$, of which $40 \% \mathrm{R} 0$ resections [26].

Selected retrospective single-institution experiences over resectable BLR and $\mathrm{LA} \mathrm{PaC}$ report $\mathrm{OS}$ up to 43.4 months in resected patients following chemotherapy or chemoradiation [27]. According to Mellon and colleagues, patients with BLR or LA PaC and sufficient response to neoadjuvant multi-agent chemotherapy and stereotactic body radiation therapy have similar or improved perioperative and long-term survival outcomes compared to upfront resection patients [28]. In this paper neoadjuvant therapy in BLR-LA patients was compared to upfront resected patients. In the ITT analysis the neoadjuvant group had a worse survival (17.0 vs 22.1 months, $p=0.029)$; such comparison has little significance because in the first group $61.6 \%$ of patients was eventually unresectable while in the upfront surgery group accounted only resected patients. Moreover, patients of the upfront surgery group who failed to receive adjuvant treatment $(20.3 \%)$ were excluded from analysis. Indeed, there was no significant difference in survival between the two groups among only resected patients (33.5 vs 23.1 months, $p=0.057)[28]$.

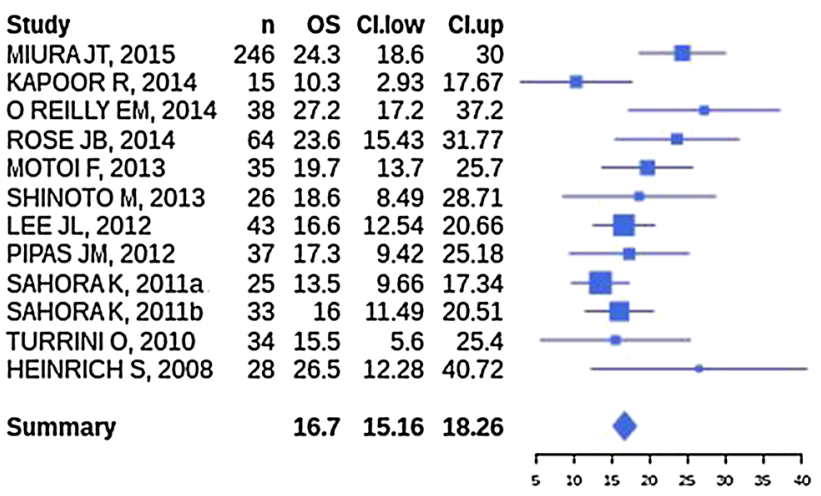

Fig. 4 Forest plot ITT-OS

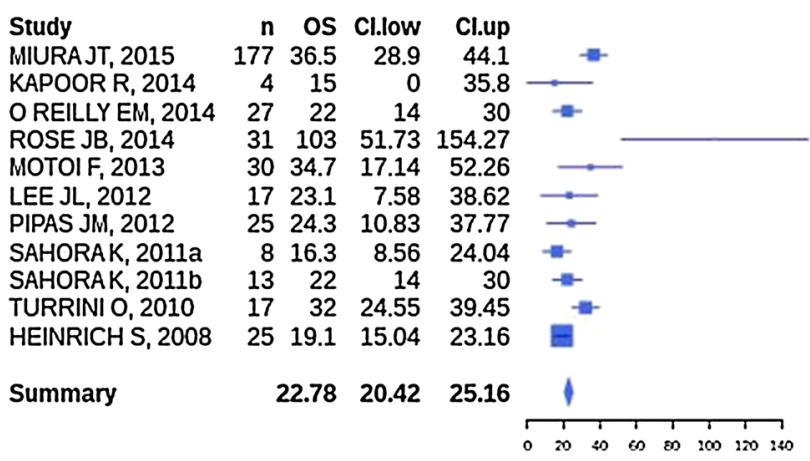

Fig. 5 Forest plot resected OS

In this meta-analysis including resectable, BLR and LA $\mathrm{PaC}$, we observe a protocol achievement of $65 \%$ with an R0 rate of $94 \%$ and an ITT survival of 16.7 months. The subgroup analysis restricted to resectable patients shows an ITT survival of 18.16 months, and among them eventually resected patients have OS of 20.87 months. Overall, two patients out of three have been treated as intended/planned.

Surprisingly, survival of patients eventually resected among resectable ones wasn't better than overall survival of resected patients ( 20.87 vs 22.78 months). This may be explained by the fact that preoperative staging is far from being accurate. As already said, to the best of clinical practice, one out of five patients is wrongly taken to the OR with a curative intent while having a LA PaC.

In Miura' study, while in the ITT analysis clinically BLR disease was an independent poor prognostic indicator, among resected patients OS did not differ between preoperatively classified resectable and BLR patients [7]. This confirms that once resected, preoperative staging doesn't influence patients' outcomes.

Histologic confirmation of the disease is mandatory before administering neoadjuvant treatment even though up to $16 \%$ of preoperatively cyto/histologically diagnosed pancreatic cancers eventually receive a final pathological diagnosis other than $\mathrm{PaC}$ [18], thus receiving a useless 


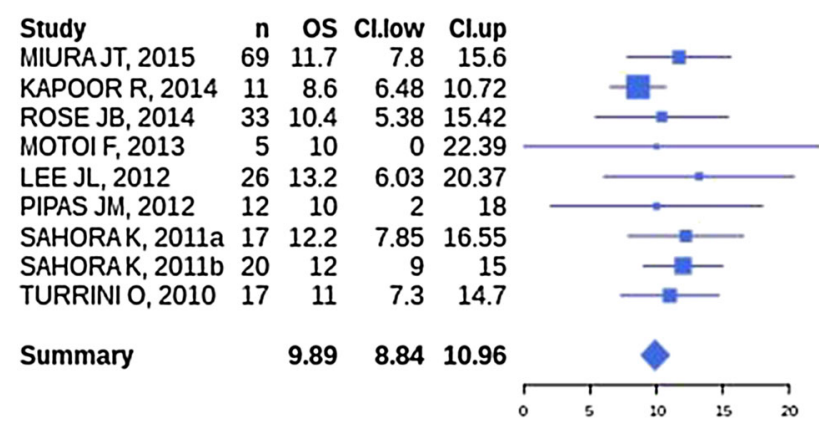

Fig. 6 Forest plot unresectable OS

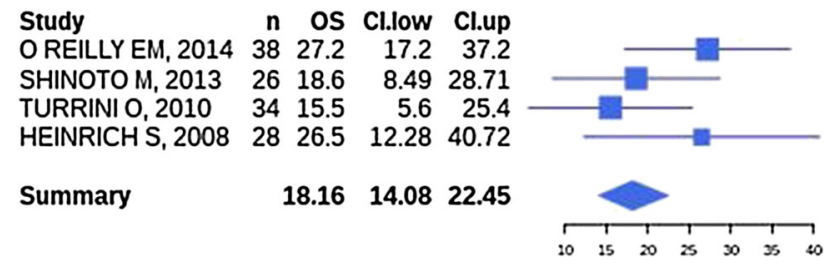

Fig. 7 Forest plot resectable ITT-OS

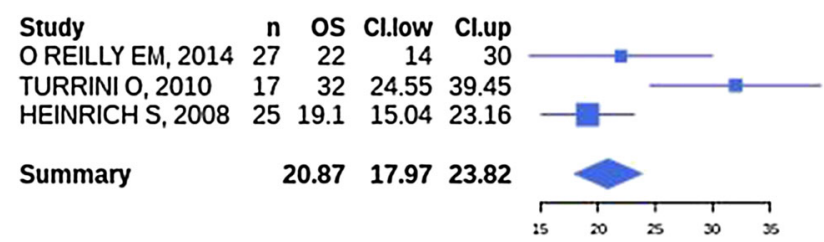

Fig. 8 Forest plot resected among resectable OS

neoadjuvant treatment. In Golcher' study pathological diagnosis of $\mathrm{PaC}$ at biopsy has been rejected in $4.5 \%$ of resected patients (because of the finding of a distal choledochal adenocarcinoma and a duodenal adenocarcinoma) [25].

The use of different classifications over time makes extremely difficult the interpretation of the literature. NCCN guidelines endorse the consensus statement of the Society of Abdominal Radiology and the American Pancreatic Association [29] to define resectable, borderline resectable and locally advanced pancreatic cancer. The unanimous use of this classification might clarify the impact of neoadjuvant treatments on the survival of those patients.

Outcomes tend to be better outside an RCT context; the literature is influencing our conduct, but strong evidences come only from well-designed randomized trials. More effort should be addressed toward the comprehension of the potential benefit that patients could gain from neoadjuvant approach.

\section{Compliance with ethical standards}

Conflict of interest All authors declare that they have no conflict of interest.
Ethical approval This article does not contain any studies with human participants or animals performed by any of the authors.

\section{References}

1. American Cancer Society. Pancreatic cancer detailed guide. http://www.cancer.org/cancer/pancreaticcancer/detailedguide/ pancreatic-cancer-survival-rates. Accessed 12 Dec 2016.

2. NCCN Clinical Practice Guidelines in Oncology (NCCN Guidelines ${ }^{\circledR}$ ) Pancreatic Adenocarcinoma Version 2.2016, 08/16/ 16 (c) National Comprehensive Cancer Network, Inc. 2016. https://www.nccn.org/professionals/physician_gls/pdf/pancreatic. pdf. Accessed 12 Dec 2016.

3. Allen VB, Gurusamy KS, Takwoingi Y, Kalia A, Davidson BR. Diagnostic accuracy of laparoscopy following computed tomography $(\mathrm{CT})$ scanning for assessing the resectability with curative intent in pancreatic and periampullary cancer. Cochrane Database Syst Rev. 2016;7:CD009323.

4. Katz MH, Pisters PW, Evans DB, Sun CC, Lee JE, Fleming JB, Vauthey JN, Abdalla EK, Crane CH, Wolff RA, Varadhachary GR, Hwang RF. Borderline resectable pancreatic cancer: the importance of this emerging stage of disease. J Am Coll Surg. 2008;206(5):833-46.

5. Ramacciato G, Nigri G, Petrucciani N, Pinna AD, Ravaioli M, Jovine E, Minni F, Grazi GL, Chirletti P, Tisone G, Napoli N, Boggi U. Pancreatectomy with mesenteric and portal vein resection for borderline resectable pancreatic cancer: multicenter study of 406 patients. Ann Surg Oncol. 2016;23(6):2028-37.

6. Higgins JP, Thompson SG, Spiegelhalter DJ. A re-evaluation of random-effects meta-analysis. J R Stat Soc Ser A Stat Soc. 2009;172(1):137-59.

7. Miura JT, Krepline AN, George B, Ritch PS, Erickson BA, Johnston FM, Oshima K, Christians KK, Evans DB, Tsai S. Use of neoadjuvant therapy in patients 75 years of age and older with pancreatic cancer. Surgery. 2015;158(6):1545-55. doi:10.1016/j. surg.2015.06.017.

8. Kapoor R, Khosla D, Gupta R, Bahl A, Shukla AK, Sharma SC. Role of neoadjuvant concurrent chemoradiation in locally advanced unresectable pancreatic cancer: a feasibility study at tertiary care centre. Indian J Cancer. 2014;51(2):176-9. doi:10. 4103/0019-509X.138295.

9. O'Reilly EM, Perelshteyn A, Jarnagin WR, Schattner M, Gerdes H, Capanu M, Tang LH, LaValle J, Winston C, DeMatteo RP, D'Angelica M, Kurtz RC, Abou-Alfa GK, Klimstra DS, Lowery MA, Brennan MF, Coit DG, Reidy DL, Kingham TP, Allen PJ. A single-arm, nonrandomized phase II trial of neoadjuvant gemcitabine and oxaliplatin in patients with resectable pancreas adenocarcinoma. Ann Surg. 2014;260(1):142-8. doi:10.1097/SLA. 0000000000000251.

10. Rose JB, Rocha FG, Alseidi A, Biehl T, Moonka R, Ryan JA, Lin B, Picozzi V, Helton S. Extended neoadjuvant chemotherapy for borderline resectable pancreatic cancer demonstrates promising postoperative outcomes and survival. Ann Surg Oncol. 2014;21(5):1530-7. doi:10.1245/s10434-014-3486-z.

11. Motoi F, Ishida K, Fujishima F, Ottomo S, Oikawa M, Okada T, Shimamura H, Takemura S, Ono F, Akada M, Nakagawa K, Katayose Y, Egawa S, Unno M. Neoadjuvant chemotherapy with gemcitabine and S-1 for resectable and borderline pancreatic ductal adenocarcinoma: results from a prospective multi-institutional phase 2 trial. Ann Surg Oncol. 2013;20(12):3794-801. doi:10.1245/s10434-013-3129-9.

12. Shinoto M, Yamada S, Yasuda S, Imada H, Shioyama Y, Honda H, Kamada T, Tsujii H, Saisho H, Working Group for Pancreas Cancer. Phase 1 trial of preoperative, short-course carbon-ion 
radiotherapy for patients with resectable pancreatic cancer. Cancer. 2013;119(1):45-51. doi:10.1002/cncr.27723.

13. Lee JL, Kim SC, Kim JH, Lee SS, Kim TW, Park DH, Seo DW, Lee SK, Kim MH, Kim JH, Park JH, Shin SH, Han DJ. Prospective efficacy and safety study of neoadjuvant gemcitabine with capecitabine combination chemotherapy for borderline-resectable or unresectable locally advanced pancreatic adenocarcinoma. Surgery. 2012;152(5):851-62. doi:10.1016/j.surg.2012. 03.010.

14. Pipas JM, Zaki BI, McGowan MM, Tsapakos MJ, Ripple GH, Suriawinata AA, Tsongalis GJ, Colacchio TA, Gordon SR, Sutton JE, Srivastava A, Smith KD, Gardner TB, Korc M, Davis TH, Preis M, Tarczewski SM, Mackenzie TA, Barth RJ Jr. Neoadjuvant cetuximab, twice-weekly gemcitabine, and intensitymodulated radiotherapy (IMRT) in patients with pancreatic adenocarcinoma. Ann Oncol. 2012;23(11):2820-7. doi:10.1093/ annonc/mds 109 .

15. Sahora K, Kuehrer I, Schindl M, Koelblinger C, Goetzinger P, Gnant M. NeoGemTax: gemcitabine and docetaxel as neoadjuvant treatment for locally advanced nonmetastasized pancreatic cancer. World J Surg. 2011;35(7):1580-9. doi:10.1007/s00268011-1113-8.

16. Sahora K, Kuehrer I, Eisenhut A, Akan B, Koellblinger C, Goetzinger P, Teleky B, Jakesz R, Peck-Radosavljevic M, Ba'ssalamah A, Zielinski C, Gnant M. NeoGemOx: gemcitabine and oxaliplatin as neoadjuvant treatment for locally advanced, nonmetastasized pancreatic cancer. Surgery. 2011;149(3): 311-20. doi:10.1016/j.surg.2010.07.048.

17. Turrini O, Ychou M, Moureau-Zabotto L, Rouanet P, Giovannini M, Moutardier V, Azria D, Delpero JR, Viret F. Neoadjuvant docetaxel-based chemoradiation for resectable adenocarcinoma of the pancreas: new neoadjuvant regimen was safe and provided an interesting pathologic response. Eur J Surg Oncol. 2010;36(10):987-92. doi:10.1016/j.ejso.2010.07.003.

18. Heinrich S, Pestalozzi BC, Schäfer M, Weber A, Bauerfeind P, Knuth A, Clavien PA. Prospective phase II trial of neoadjuvant chemotherapy with gemcitabine and cisplatin for resectable adenocarcinoma of the pancreatic head. J Clin Oncol. 2008; 26(15):2526-31. doi:10.1200/JCO.2007.15.5556.

19. Callery MP, Chang KJ, Fishman EK, Talamonti MS, William Traverso L, Linehan DC. Pretreatment assessment of resectable and borderline resectable pancreatic cancer: expert consensus statement. Ann Surg Oncol. 2009;16(7):1727-33. doi:10.1245/s10434-009-0408-6.

20. Appel BL, Tolat P, Evans DB, Tsai S. Current staging systems for pancreatic cancer. Cancer J. 2012;18(6):539-49. doi:10.1097/ PPO.0b013e318278c5b5.

21. Tempero M, Arnoletti JP, Ben-Josef E, Bhargava P, Casper ES, Kim P, Malafa MP, Nakakura EK, Shibata S, Talamonti M, Wang H, Willett C. Pancreatic adenocarcinoma. Clinical practice guidelines in oncology. J Natl Compr Canc Netw. 2007:5(10):998-1033.
22. National Comprehensive Cancer Network. Pancreatic adenocarcinoma. NCCN guidelines version 1.2008. Accessed 19 Nov 2007.

23. D’Angelo FA, Antolino L, La Rocca M, Petrucciani N, Magistri P, Aurello P, Ramacciato G. Adjuvant and neoadjuvant therapies in resectable pancreatic cancer: a systematic review of randomized controlled trials. Med Oncol. 2016;33(3):28. doi:10.1007/ s12032-016-0742-z.

24. Palmer DH, Stocken DD, Hewitt H, Markham CE, Hassan AB, Johnson PJ, Buckels JA, Bramhall SR. A randomized phase 2 trial of neoadjuvant chemotherapy in resectable pancreatic cancer: gemcitabine alone versus gemcitabine combined with cisplatin. Ann Surg Oncol. 2007;14(7):2088-96. doi:10.1245/ s10434-007-9384-x.

25. Golcher H, Brunner TB, Witzigmann H, Marti L, Bechstein WO, Bruns C, Jungnickel H, Schreiber S, Grabenbauer GG, Meyer T, Merkel S, Fietkau R, Hohenberger W. Neoadjuvant chemoradiation therapy with gemcitabine/cisplatin and surgery versus immediate surgery in resectable pancreatic cancer. Results of the first prospective randomized phase II trial. Strahlenther Onkol. 2015;191(1):7-16. doi:10.1007/s00066-014-0737-7.

26. Landry J, Catalano PJ, Staley C, Harris W, Hoffman J, Talamonti $\mathrm{M}, \mathrm{Xu}$ N, Cooper H, Benson AB 3rd. Randomized phase II study of gemcitabine plus radiotherapy versus gemcitabine, 5-fluorouracil, and cisplatin followed by radiotherapy and 5-fluorouracil for patients with locally advanced, potentially resectable pancreatic adenocarcinoma. J Surg Oncol. 2010; 101(7):587-92. doi:10.1002/jso.21527.

27. Cloyd JM, Katz MH, Prakash L, Varadhachary GR, Wolff RA, Shroff RT, Javle M, Fogelman D, Overman M, Crane CH, Koay EJ, Das P, Krishnan S, Minsky BD, Lee JH, Bhutani MS, Weston B, Ross W, Bhosale P, Tamm EP, Wang H, Maitra A, Kim MP, Aloia TA, Vauthey JN, Fleming JB, Abbruzzese JL, Pisters PW, Evans DB, Lee JE. Preoperative therapy and pancreatoduodenectomy for pancreatic ductal adenocarcinoma: a 25-year single-institution experience. J Gastrointest Surg. 2017;21(1): 164-74.

28. Mellon EA, Strom TJ, Hoffe SE, Frakes JM, Springett GM, Hodul PJ, Malafa MP, Chuong MD, Shridhar R. Favorable perioperative outcomes after resection of borderline resectable pancreatic cancer treated with neoadjuvant stereotactic radiation and chemotherapy compared with upfront pancreatectomy for resectable cancer. $\mathrm{J}$ Gastrointest Oncol. 2016;7(4):547-55.

29. Al-Hawary MM, Francis IR, Chari ST, Fishman EK, Hough DM, Lu DS, Macari M, Megibow AJ, Miller FH, Mortele KJ, Merchant NB, Minter RM, Tamm EP, Sahani DV, Simeone DM. Pancreatic ductal adenocarcinoma radiology reporting template: consensus statement of the Society of Abdominal Radiology and the American Pancreatic Association. Radiology. 2014;270(1): 248-60. doi:10.1148/radiol.13131184. 